UDC 519.64

Вестник СПбГУ. Прикладная математика. Информатика... 2019. Т. 15. Вып. 3

MSC 65L80, 45D05

\title{
Construction of implicit multistep methods for solving integral algebraic equations*
}

\author{
M. V. Bulatov ${ }^{1}$, M. Hadizadeh ${ }^{2}$, E. V. Chistyakova ${ }^{1}$ \\ 1 V. M. Matrosov Institute for System Dynamics and Control Theory of Siberian Branch \\ of Russian Academy in Sciences, 134, ul. Lermontova, Irkutsk, \\ 664033, Russian Federation \\ 2 K. N. Toosi University of Technology, 470, Mirdamad Ave. West, Tehran, \\ 19697, Iran
}

For citation: Bulatov M. V., Hadizadeh M., Chistyakova E. V. Construction of implicit multistep methods for solving integral algebraic equations. Vestnik of Saint Petersburg University. Applied Mathematics. Computer Science. Control Processes, 2019, vol. 15, iss. 3, pp. 310-322. https://doi.org/10.21638/11702/spbu10.2019.302

This paper discusses techniques for construction of implicit stable multistep methods for solving systems of linear Volterra integral equations with a singular matrix multiplying the leading part, which means that systems under consideration comprise Volterra equations of the first kind as well as Volterra equations of the second kind. Methods for solving first kind Volterra equations so far have been justified only for some special cases, for example, for linear equations with a kernel that does not vanish on the diagonal for all points of the segment. We present a theoretical analysis of solvability of the systems under study, single out classes of two- and three-step numerical methods of order two and three, respectively, and provide examples to illustrate our theoretical assumptions. The experimental results indicate that the stability of the methods can be controlled by some weight parameter that should be chosen from a prescribed interval to provide the necessary stability of the algorithms.

Keywords: system of Volterra equations, integral algebraic equation, multistep method, quadrature formulas, stability analysis.

1. Introduction. Volterra integral equations have many useful applications in describing numerous applied problems and events of the real world. Nowadays, the theory of numerical treatment of the second kind Volterra equations is fairly well-developed, and historical surveys on this topic as well as an extended bibliography can be found in the monographs [1-4]. Methods for solving first kind Volterra equations so far have been justified only for some special cases, for example, for linear equations with a kernel that does not vanish on the diagonal for all points of the segment. Many research papers address this type of problems, which are widely covered in the monographs listed above, as well as in $[5-8]$.

This paper considers linear systems of Volterra equations with a singular square matrix multiplying the leading part. Such systems are commonly referred to as integral algebraic equations (IAEs) and generally have the form

$$
A(t) x(t)+\int_{0}^{t} K(t, s) x(s) d s=f(t), \quad 0 \leqslant s \leqslant t \leqslant 1
$$

* M. V. Bulatov and E. V. Chistyakova acknowledge the financial support from the Russian Foundation for Basic Research (projects N 18-51-54001, 18-01-00643, 18-29-10019).

(C) Санкт-Петербургский государственный университет, 2019 
where $A(t), K(t, s)$ are $n \times n$ matrices, $f(t)$ and $x(t)$ are the given and the desired vectorfunctions, respectively. It is assumed that the elements of $A(t), K(t, s), f(t)$ are sufficiently smooth and

$$
\operatorname{det} A(t) \equiv 0 .
$$

Here by the solution of the problem (1), (2), we understand any continuous vectorfunction $x(t)$ that turns (1) into an identity. Note that if $n=1$, we obtain the first kind Volterra equation.

Integral algebraic equations naturally arise in many mathematical modeling processes, e. g. the kernel identification problems in heat conduction and viscoelasticity [9], evolution of a chemical reaction within a small cell [10], the two dimensional biharmonic equation in a semi-infinite strip [11], dynamic processes in chemical reactors [12] and Kirchhoff's laws [1] (for further applications see [1, 13] and references therein).

The first papers on the qualitative and numerical analysis of IAEs were published in the end of 1980s. Drawing on the available literature, it appears that the first paper addressing IAEs was [14], followed later by [15]. However, by present time there have been published no more than 30 papers addressing numerical treatment of such problems. The majority of papers considers IAEs of the semi-explicit form and employ for their solution collocation type methods. The polynomial spline collocation method and its convergence results were studied in [16]. In [17], the authors presented the Jacobi collocation method including the matrix-vector multiplication representation for IAEs of index-2. A posteriori error estimation is also obtained for the Legendre collocation method in [18]. These methods were extended to the semi-explicit IAEs of indices 1 and 2, as well as to the IAEs with weakly singular kernels in [19]. A multistep method based on the Adams quadrature rules and extrapolation formulas was constructed in [20]. An approach based on the block pulse functions was proposed in [21]. The paper [22] proposes a regularization method for linear IAEs. Recent studies can be found in the works [12, 23], which present an analysis of piecewise polynomial collocation solutions for general systems of linear IAEs based on the notions of the tractability index and the $\nu$-smoothing property by decoupling the system into the inherent system of regular Volterra integral equations.

Actually, most of the numerical methods discussed so far, have been the projectionbased approach. The main issue with IAEs is that they explicitly or implicitly comprise Volterra equations of the first kind which causes these equations to belong to the class of moderately ill-posed problems. However, owing to some restrictive conditions as well as instability of numerical differentiation, the reduction of the problem to the regular system of second kind Volterra equations may not be always practical from a numerical point of view.

Another difficulty is related to the high computational complexity of the projection based methods, since the associated projectors onto the null spaces have to be computed at every integration step, which makes the numerical approach rather expensive.

Following [4], the application of some higher order multistep methods to this type of equations may also result in unstable processes. This means that algorithms based on the Adams, Simpson and Newton-Cotes formulas might be unstable, when applied to IAEs.

The aim of the current research is to address the instability issues of the numerical methods and propose the techniques for handling them. The outline of this paper is as follows. In section 2, we discuss some useful tools for theoretical analysis. Section 3 provides a general idea of a stable algorithm for IAEs (1), whereas section 4 presents stable second and third order methods together with results of numerical experiments on some test problems. 
2. Preliminaries and some useful lemmas. Below, we will need the following statements and definitions.

Definition 1 [24]. The matrix pencil $\lambda A(t)+B(t)$ satisfies the rank-degree criterion on the segment $[0,1]$ (in other words, the pencil is index one or has a simple structure), if

$$
\operatorname{rank} A(t)=\operatorname{deg}(\operatorname{det}(\lambda A(t)+B(t)))=m=\mathrm{const} \quad \forall t \in[0,1],
$$

where $\lambda$ is scalar, and $\operatorname{deg}($.$) denotes the degree of the polynomial.$

The following theorem from [14], describes the conditions under which the IAE (1) possesses a unique continuous solution.

Theorem 1 [14]. Let the problem (1), (2) fulfill the following conditions:

1) $A(t) \in C_{[0,1]}^{1}, \quad f(t) \in C_{[0,1]}^{1}, \quad K(t, s) \in C_{\Delta}^{1}, \quad \Delta=\{0 \leqslant s \leqslant t \leqslant 1\}$;

2) the matrix pencil $\lambda A(t)+K(t, t)$ satisfies the rank-degree criterion on the whole segment $[0,1]$;

3) $\operatorname{rank} A(0)=\operatorname{rank}(A(0) \mid f(0))$.

Then, the problem (1), (2) has a unique continuous solution.

Note that if $n=1$, i. e. if we deal with the first kind Volterra equation, the second condition of Theorem 1 means that $K(t, t) \neq 0, \forall t \in[0,1]$, whereas the third condition has the form $f(0)=0$. Those are the classic solvability conditions for the first kind Volterra equation (see, e. g., [3, 5]).

Systems that satisfy Theorem 1 can be considered as index-1 IAEs in the sense of [14], which means that there exists a linear first order differential operator that transforms the original system to a regular system of Volterra equations of the second kind [25].

Definition 2 [14]. Let there exist a differential operator $\Omega_{l}=\sum_{j=0}^{l} L_{j}(t)(d / d t)^{j}, \quad t \in$ $T$, where $L_{j}(t)$ are $n \times n$ continuous matrices, such that

$$
\begin{gathered}
\Omega_{l}\left[A(t) y(t)+\int_{0}^{t} K(t, s) y(s)\right]=\tilde{A}(t) y+\int_{0}^{t} \tilde{K}(t, s) y(s) d s, \\
\operatorname{det} \tilde{A}(t) \neq 0 \quad \forall t \in T .
\end{gathered}
$$

Then the operator $\Omega_{l}$ is said to be the left regularizing operator and the smallest possible number $l$ is said to be the index of the IAE (1).

The concept of index for IAEs originates from the theory of differential-algebraic equations (DAEs), which is a crucial issue in theoretical and numerical analysis of these equations (where index is considered a key to theoretical and numerical analysis). There are several definitions of index for DAEs, most of which are covered in [26]. However, the situation with IAEs is not so clear [12], so in this paper we employ Definition 1 as most suitable for our purposes.

3. Numerical algorithms. This section presents some stable numerical algorithms based on multistep methods for numerical solution of IAEs. In contrast to the studies previously done in [20], we now attempt to design an implicit scheme, which is expected to have better convergence and better stability properties.

On the segment $[0,1]$, set the uniform mesh $t_{i}=i h, \quad i=0,1, \ldots, N, \quad h=1 / N$ and let $q(t)$ be a function from $C_{[0,1]}^{p+1}$. Then we will find $\int_{0}^{t_{i+1}} q(s) d s$, using the $k$-step formula 


$$
\begin{gathered}
\int_{0}^{t_{i+1}} q(s) d s=\int_{0}^{t_{k}} q(s) d s+\sum_{j=k}^{i} \int_{t_{j}}^{t_{j+1}} q(s) d s \simeq h \sum_{l=0}^{k} a_{l} q\left(t_{l}\right)+\sum_{j=k}^{i} h \sum_{l=0}^{k} b_{l} q\left(t_{j+1-l}\right)=h \sum_{l=0}^{i+1} \omega_{i+1, l} q_{l} \\
(i=k, k+1, \ldots, N-1),
\end{gathered}
$$

where the weights $\omega_{i+1, l}$ are the linear combinations of $a_{l}$ and $b_{l}$, which are found from the order conditions: it is well-known (see, e. g., $[3,4])$ that if the following equalities are satisfied:

$$
\begin{gathered}
\left\{\begin{array}{c}
\sum_{l=0}^{k} a_{l}=k, \\
\sum_{l=0}^{k} l \cdot a_{l}=\frac{k^{2}}{2}, \\
\cdots \\
\sum_{l=0}^{k} l^{m-1} \cdot a_{l}=\frac{k^{m}}{m},
\end{array}\right. \\
\left\{\begin{array}{c}
\sum_{l=0}^{k} b_{l}=1, \\
\sum_{l=0}^{k}(1-l) b_{l}=\frac{1}{2}, \\
\cdots \\
\sum_{l=0}^{k}(1-l)^{m-1} b_{l}=\frac{1}{m},
\end{array}\right.
\end{gathered}
$$

then the quadrature formula (3) has order $m$.

If we denote $A_{i+1}=A\left(t_{i+1}\right), K_{i+1, l}=K\left(t_{i+1}, t_{l}\right), f_{i+1}=f\left(t_{i+1}\right), x_{i+1} \simeq x\left(t_{i+1}\right)$, then, taking into account the formula for representation of the integral term (3), the multistep ( $k$-step) methods for solving IAEs (1) have the form

$$
A_{i+1} x_{i+1}+h \sum_{l=0}^{i+1} \omega_{i+1, l} K_{i+1, l} x_{l}=f_{i+1}, \quad i=k-1, k, \ldots, N-1 .
$$

It is assumed that the values $x_{0}, x_{1}, \ldots, x_{k-1}$ have been found with the prescribed accuracy. If $m=k+1$ in (4) and (5), we obtain the well-known implicit Adams type methods, which are unstable. Therefore, set $m<k+1$. In this case, the coefficients $b_{l}, a_{l}, l=0,1, \ldots, k$, are not uniquely defined and satisfy the linear system of algebraic equations of dimension $m \times(k+1)$. For stability reasons, we also have to assume that the roots, generally complex ones, of the polynomial

$$
\sum_{l=0}^{k} b_{l} \nu^{k-l}
$$

belong to the unit disk and that the boundary of the disk does not have multiple roots.

Convergence of method (6) is provided by the following theorem.

Theorem 2. Let the problem (1), (2) fulfill the conditions:

1) $x(t), A(t), f(t) \in C_{[0,1]}^{k}, K(t, s) \in C_{\Delta}^{(k+1)}, \Delta=\{0 \leqslant s \leqslant t \leqslant 1\}$;

2) the matrix pencil $\lambda A(t)+K(t, t)$ satisfies the rank-degree criterion on the whole segment $[0,1]$;

3) $\operatorname{rank} A(0)=\operatorname{rank}(A(0) \mid f(0))$;

4) the initial values are such that $\left\|x_{j}-x\left(t_{j}\right)\right\| \leqslant R h^{k}, \quad R<\infty, j=0,1, \ldots, k-1$;

$5)$ the roots of the characteristic polynomial (7) belong to a unit disk and the boundary of the disk does not contain multiple roots.

Then, the method (6) converges to the exact solution with order $k$, $i$. e. the following estimate holds: $\left\|x_{i}-x\left(t_{i}\right)\right\|=O\left(h^{k}\right), \quad i=k, k+1, \ldots, N-1$. 
Since the proof of Theorem 2 happened to be pretty much similar to that of Theorem 3.1 from [20], we do not present it here.

4. Second and third order methods: stability analysis. Here we address the properties of $k$-step methods of order $k$. It is assumed that either we are given the exact starting values $x_{0}, x_{1}, \ldots, x_{k-1}$ or they have been found with the accuracy $O\left(h^{k+1}\right)$.

Now we will show how to design stable two-step second order methods. In this case, the integral approximation (3) have the form

$$
\begin{gathered}
\int_{0}^{t_{i+1}} q(\tau) d \tau=\int_{0}^{t_{2}} q(\tau) d \tau+\sum_{j=2}^{i} \int_{t_{j}}^{t_{j+1}} q(\tau) d \tau \simeq \\
\simeq h \sum_{l=0}^{2} a_{l} q\left(t_{l}\right)+\sum_{j=2}^{i} h \sum_{l=0}^{2} b_{l} g\left(t_{j+1-l}\right)=h \sum_{l=0}^{i+1} \omega_{i+1, l} g_{l},
\end{gathered}
$$

whereas the order conditions (4), (5) are reduced to

$$
\begin{gathered}
\left\{\begin{array}{c}
a_{0}+a_{1}+a_{2}=2, \\
a_{1}+2 a_{2}=2,
\end{array}\right. \\
\left\{\begin{array}{c}
b_{2}+b_{1}+b_{0}=1, \\
-b_{2}+b_{0}=\frac{1}{2} .
\end{array}\right.
\end{gathered}
$$

Set $a_{2}=b_{0}=M, M \in \mathbb{R}$, and find $a_{0}, a_{1}, b_{1}, b_{2}$. Then we derive the following values for the weights $\omega_{i+1, l}$ :

$$
\omega_{i+1, l}=\left(\begin{array}{ccccccc}
M & 2-2 M & M & & & & \\
M & \frac{3}{2}-M & \frac{3}{2}-M & M & & & \\
M & \frac{3}{2}-M & 1 & \frac{3}{2}-M & M & & \\
M & \frac{3}{2}-M & 1 & 1 & \frac{3}{2}-M & M & \\
\ldots & \ldots & \ldots & \ldots & \ldots & \ldots & \ldots
\end{array}\right)
$$

Now we have to find the values of $M$ for which the two-step method is stable. The characteristic polynomial (7) takes the form

$$
M \nu^{2}+\left(\frac{3}{2}-2 M\right) \nu+\left(M-\frac{1}{2}\right)=0,
$$

and the two-step method (6) is stable, if the roots of (9) belong to the unit disk and the boundary of the disk does not have multiple roots. To verify this, we employ a standard technique: we will study the image of the exterior of the unit disk under the mapping $\nu=\frac{\alpha+1}{\alpha-1}$. We obtain

$$
(M+1) \alpha^{2}+\alpha+(4 M-2)=0 .
$$

Apply the Routh-Hurwitz criterion (see, e. g., [27]) to (10). Then we see that the real part of $\alpha$ is negative, if

$$
\left\{\begin{array}{c}
M+1 \geqslant 0, \\
4 M-2 \geqslant 0 .
\end{array}\right.
$$


These inequalities entail that the two-step second order methods (5) with the weights (8) are stable, if $M \in\left[\frac{1}{2},+\infty\right)$.

The weights of the two-step third order method can be found from the conditions

$$
\begin{gathered}
\left\{\begin{array}{c}
a_{0}+a_{1}+a_{2}+a_{3}=3, \\
a_{1}+2 a_{2}+3 a_{3}=\frac{9}{2}, \\
a_{1}+4 a_{2}+9 a_{3}=9,
\end{array}\right. \\
\left\{\begin{array}{c}
b_{3}+b_{2}+b_{1}+b_{0}=1 \\
-2 b_{3}-b_{2}+b_{0}=\frac{1}{2} . \\
4 b_{3}+b_{2}+b_{0}=\frac{1}{3} .
\end{array}\right.
\end{gathered}
$$

Set $a_{3}=b_{0}=M$. Then the weight matrix has the form

$$
\omega_{i+1, l}=\left(\begin{array}{cccccccc}
\frac{3}{4}-M & 3 M & \frac{9}{4}-3 M & M & & & & \\
\frac{3}{4}-M & \frac{5}{12}+2 M & \frac{11}{12} & \frac{23}{12}-2 M & M & & & \\
\frac{3}{4}-M & \frac{5}{12}+2 M & \frac{16}{12}-M & \frac{7}{12}+M & \frac{23}{12}-2 M & M & & \\
\frac{3}{4}-M & \frac{5}{12}+2 M & \frac{16}{12}-M & 1 & \frac{7}{12}+M & \frac{23}{12}-2 M & M & \\
\frac{3}{4}-M & \frac{5}{12}+2 M & \frac{16}{12}-M & 1 & 1 & \frac{7}{12}+M & \frac{23}{12}-2 M & M \\
\ldots & \ldots & \ldots & \ldots & \ldots & \ldots & \ldots & \ldots
\end{array}\right) .
$$

Our aim is to find such values of $M$ that provide stability of the method. The characteristic polynomial has the form

$$
M \nu^{3}+\left(\frac{23}{12}-3 M\right) \nu^{2}+\left(3 M-\frac{16}{12}\right) \nu+\left(\frac{5}{12}-M\right)=0 .
$$

By using the substitution $\nu=\frac{\alpha+1}{\alpha-1}$, we obtained the the polynomial

$$
\alpha^{3}+2 \alpha^{2}+\frac{8}{12} \alpha+\left(8 M-\frac{11}{3}\right)=0
$$

Similarly, the Rauth-Hurwitz criterion yields that the three-step method (6) with the weight matrix (11) is stable for the class of problems under consideration, if $M \in\left[\frac{11}{24}, \frac{15}{24}\right]$.

Remark 1. To implement the numerical algorithm, we need to know values of $x(t)$ in the first $k$ points. We can use two techniques, which are widely employed in the numerical treatment of ODEs:

1) take a much smaller integration step and apply some simple algorithm based on the right point rule [14];

2) solve the problem numerically on the segment $[0, k h]$ by $k$-step collocation methods $[1,3]$. Such methods do not require to know initial values, and, since we apply them only once, there is no need to justify their stability.

In the section 5 we will test the algorithms proposed to illustrate our theoretical speculations.

5. Some experimental results. Now we present some numerical examples to clarify the accuracy and stability issues of the algorithms proposed. The multistep methods considered in the previous sections were applied to the IAE (1) on the interval $[0,1]$ for several values of $M$. The algorithms were coded in MATLAB ${ }^{\circledR}$. 
Example 1 [20].

$$
\begin{gathered}
\left(\begin{array}{cc}
1 & t \\
t & t^{2}
\end{array}\right)\left(\begin{array}{l}
x_{1}(t) \\
x_{2}(t)
\end{array}\right)+\int_{0}^{t}\left(\begin{array}{cc}
e^{t-s} & 0 \\
e^{-2 s} & e^{t+s}
\end{array}\right)\left(\begin{array}{l}
x_{1}(s) \\
x_{2}(s)
\end{array}\right) d s=\left(\begin{array}{c}
e^{t}(1+t)+t e^{-t} \\
e^{-t}\left(e^{2 t}+e^{t}+t^{2}-1\right)+t e^{t}
\end{array}\right) \\
0 \leqslant t \leqslant 1 .
\end{gathered}
$$

The exact solution is $x(t)=\left(e^{t}, e^{-t}\right)^{\top}$.

The maximum of the errors between the obtained approximate solutions of the twoand three-step methods with the corresponding weight matrices and the exact solutions for various values of $M$ and $h$ have been tabulated in Tables $1-4$ for both examples. Numerical experiments fully confirmed the theoretical estimations. As predicted, within the stability interval for $M$ the error decreases; however, if $M$ is taken outside of the stability interval, the error behavior is extremely unstable.

Figures 1-6 demonstrate the error behaviors of the methods for different values of $M$ (taken within and outside of the stability interval) and $h$.

Table 1. Two-step method error norms for Example 1

\begin{tabular}{|c|c|c|c|c|c|c|c|}
\hline$M^{h}$ & $1 / 10$ & $1 / 20$ & $1 / 40$ & $1 / 80$ & $1 / 160$ & $1 / 320$ & $1 / 640$ \\
\hline $1 / 2$ & $2.20 \mathrm{e}-02$ & $6.88 \mathrm{e}-04$ & $1.91 \mathrm{e}-04$ & $5.00 \mathrm{e}-05$ & $1.27 \mathrm{e}-05$ & $3.22 \mathrm{e}-06$ & $8.09 \mathrm{e}-07$ \\
\hline 1 & $4.30 \mathrm{e}-02$ & $1.60 \mathrm{e}-03$ & $4.92 \mathrm{e}-04$ & $1.33 \mathrm{e}-04$ & $3.46 \mathrm{e}-05$ & $8.80 \mathrm{e}-06$ & $2.22 \mathrm{e}-06$ \\
\hline 2 & $9.20 \mathrm{e}-02$ & $3.90 \mathrm{e}-00$ & $1.30 \mathrm{e}-03$ & $3.51 \mathrm{e}-04$ & $9.21 \mathrm{e}-05$ & $2.36 \mathrm{e}-05$ & $5.99 \mathrm{e}-06$ \\
\hline 10 & $1.51 \mathrm{e}-02$ & $1.51 \mathrm{e}-02$ & $6.30 \mathrm{e}-03$ & $2.10 \mathrm{e}-03$ & $5.95 \mathrm{e}-04$ & $1.58 \mathrm{e}-04$ & $4.07 \mathrm{e}-05$ \\
\hline 100 & $5.08 \mathrm{e}-02$ & $4.33 \mathrm{e}-02$ & $2.81 \mathrm{e}-02$ & $1.36 \mathrm{e}-02$ & $5.10 \mathrm{e}-03$ & $1.60 \mathrm{e}-03$ & $4.30 \mathrm{e}-04$ \\
\hline 1000 & $5.84 \mathrm{e}-02$ & $6.21 \mathrm{e}-02$ & $5.64 \mathrm{e}-02$ & $4.18 \mathrm{e}-02$ & $2.42 \mathrm{e}-02$ & $1.05 \mathrm{e}-02$ & $3.60 \mathrm{e}-03$ \\
\hline
\end{tabular}

Log error

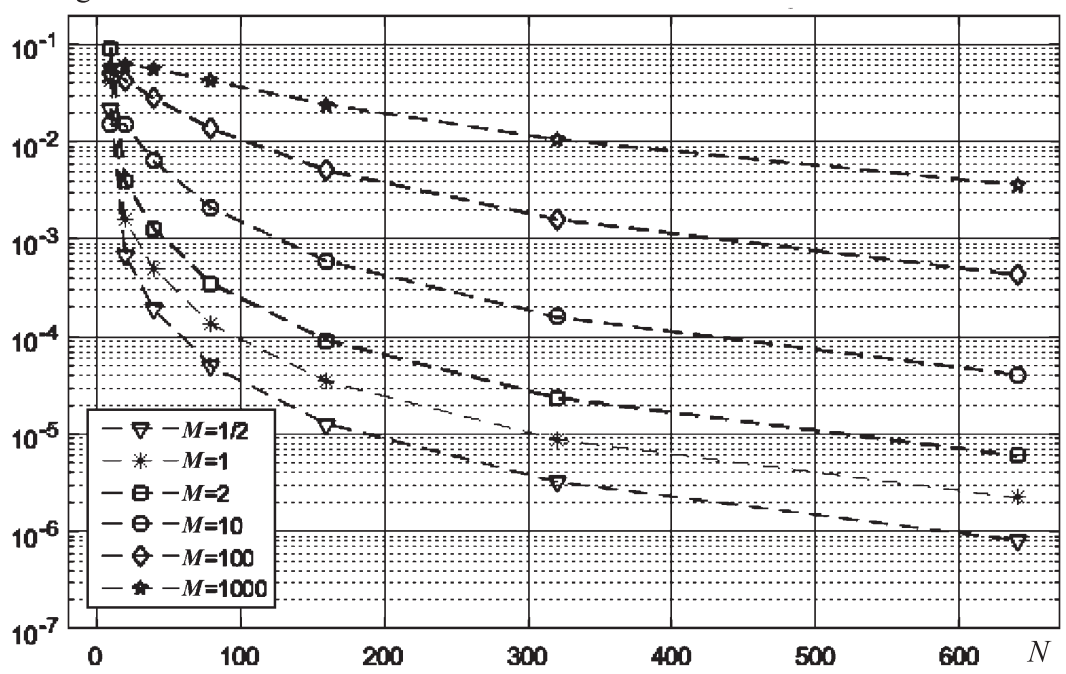

Figure 1. Error behavior for various $M$ and $h$ for Example 1 solved by the two-step method 
Table 2. Three-step method error norms for Example 1 with "stable" and "unstable" values of $M$

\begin{tabular}{|c|c|c|c|c|c|c|c|}
\hline$M^{h}$ & $1 / 10$ & $1 / 20$ & $1 / 40$ & $1 / 80$ & $1 / 160$ & $1 / 320$ & $1 / 640$ \\
\hline 0.2 & $1.71 \mathrm{e}+02$ & $8.99 \mathrm{e}+09$ & $1.40 \mathrm{e}+26$ & $\infty$ & $\infty$ & $\infty$ & $\infty$ \\
\hline 0.4 & $9.94 \mathrm{e}-04$ & $1.48 \mathrm{e}-01$ & $1.68 \mathrm{e}+04$ & $1.39 \mathrm{e}+15$ & $6.88 \mathrm{e}+37$ & $\infty$ & $\infty$ \\
\hline $11 / 24$ & $8.54 \mathrm{e}-05$ & $1.63 \mathrm{e}-05$ & $2.53 \mathrm{e}-06$ & $3.60 \mathrm{e}-07$ & $4.75 \mathrm{e}-08$ & $6.14 \mathrm{e}-09$ & $7.80 \mathrm{e}-10$ \\
\hline 0.5 & $1.19 \mathrm{e}-04$ & $2.26 \mathrm{e}-05$ & $3.38 \mathrm{e}-06$ & $4.57 \mathrm{e}-07$ & $5.91 \mathrm{e}-08$ & $7.51 \mathrm{e}-09$ & $9.46 \mathrm{e}-10$ \\
\hline 0.6 & $1.81 \mathrm{e}-04$ & $3.41 \mathrm{e}-05$ & $5.09 \mathrm{e}-06$ & $6.86 \mathrm{e}-07$ & $8.98 \mathrm{e}-08$ & $1.17 \mathrm{e}-08$ & $1.49 \mathrm{e}-09$ \\
\hline $15 / 24$ & $1.93 \mathrm{e}-04$ & $3.64 \mathrm{e}-05$ & $5.43 \mathrm{e}-06$ & $8.04 \mathrm{e}-07$ & $1.09 \mathrm{e}-07$ & $1.43 \mathrm{e}-08$ & $1.82 \mathrm{e}-09$ \\
\hline 1 & $4.85 \mathrm{e}-04$ & $3.41 \mathrm{e}-04$ & $1.00 \mathrm{e}-03$ & $1.37 \mathrm{e}-01$ & $6.79 \mathrm{e}+03$ & $2.04 \mathrm{e}+14$ & $\infty$ \\
\hline 10 & $4.90 \mathrm{e}-03$ & $5.90 \mathrm{e}-03$ & $2.81 \mathrm{e}-01$ & $4.29 \mathrm{e}-00$ & $1.27 \mathrm{e}+06$ & $1.04 \mathrm{e}+18$ & $\infty$ \\
\hline
\end{tabular}

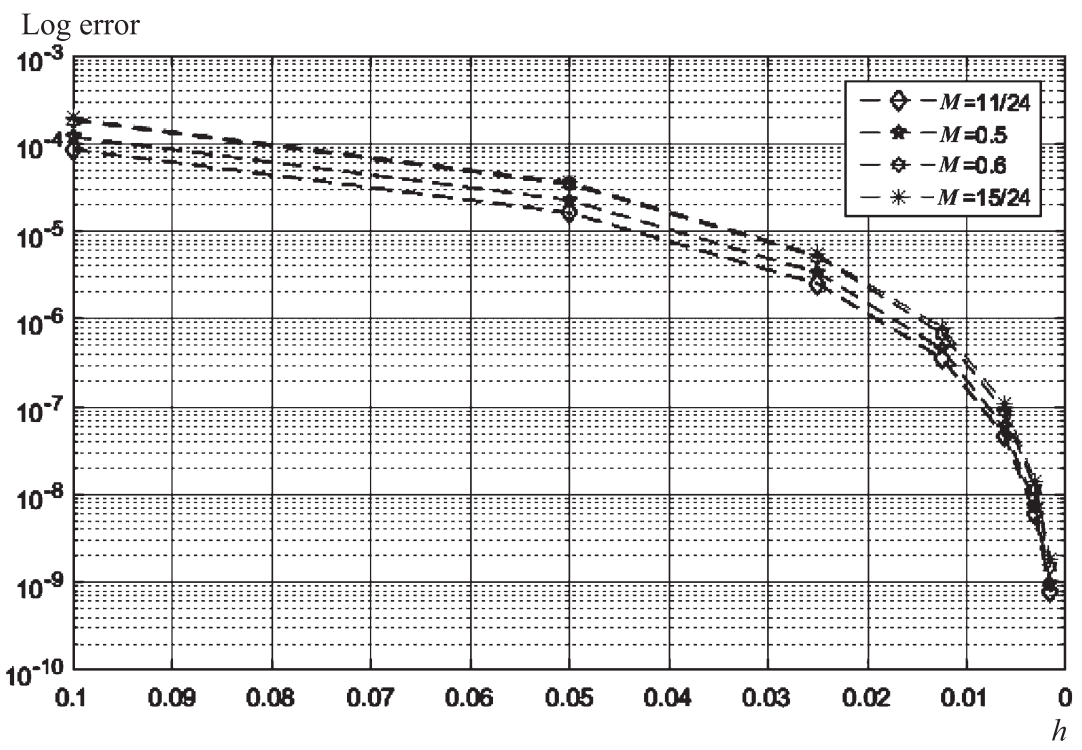

Figure 2. Error behavior for Example 1 solved by the three-step method for various $h$ and for $M$ within of the stability interval

Table 3. Two-step method error norms for Example 2

\begin{tabular}{|c|c|c|c|c|c|c|c|}
\hline$M^{h}$ & $1 / 10$ & $1 / 20$ & $1 / 40$ & $1 / 80$ & $1 / 160$ & $1 / 320$ & $1 / 640$ \\
\hline $1 / 2$ & $3.14 \mathrm{e}-02$ & $7.60 \mathrm{e}-03$ & $1.90 \mathrm{e}-03$ & $4.62 \mathrm{e}-04$ & $1.14 \mathrm{e}-04$ & $2.86 \mathrm{e}-05$ & $7.14 \mathrm{e}-06$ \\
\hline 1 & $8.24 \mathrm{e}-02$ & $2.13 \mathrm{e}-02$ & $5.20 \mathrm{e}-03$ & $1.30 \mathrm{e}-03$ & $3.12 \mathrm{e}-04$ & $7.76 \mathrm{e}-05$ & $1.93 \mathrm{e}-05$ \\
\hline 2 & $2.91 \mathrm{e}-01$ & $5.80 \mathrm{e}-02$ & $1.45 \mathrm{e}-02$ & $3.50 \mathrm{e}-03$ & $8.61 \mathrm{e}-04$ & $2.12 \mathrm{e}-04$ & $5.26 \mathrm{e}-05$ \\
\hline 10 & $7.99 \mathrm{e}-01$ & $6.52 \mathrm{e}-01$ & $9.84 \mathrm{e}-02$ & $2.47 \mathrm{e}-02$ & $6.00 \mathrm{e}-03$ & $1.50 \mathrm{e}-03$ & $3.63 \mathrm{e}-04$ \\
\hline 100 & $2.12 \mathrm{e}-00$ & $1.46 \mathrm{e}-00$ & $7.30 \mathrm{e}-01$ & $3.75 \mathrm{e}-01$ & $6.94 \mathrm{e}-02$ & $1.71 \mathrm{e}-02$ & $4.20 \mathrm{e}-03$ \\
\hline 1000 & $2.69 \mathrm{e}-00$ & $2.81 \mathrm{e}-00$ & $2.24 \mathrm{e}-00$ & $1.27 \mathrm{e}-00$ & $9.95 \mathrm{e}-01$ & $1.73 \mathrm{e}-01$ & $4.45 \mathrm{e}-02$ \\
\hline
\end{tabular}




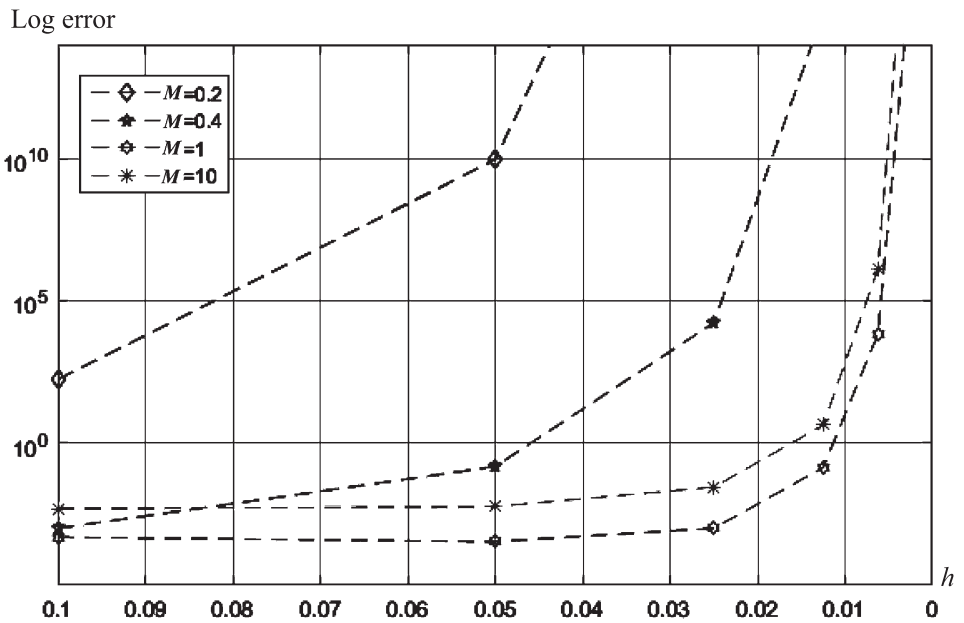

Figure 3. Error behavior for Example 1 solved by the three-step method for various $h$ and for $M$ outside of the stability interval

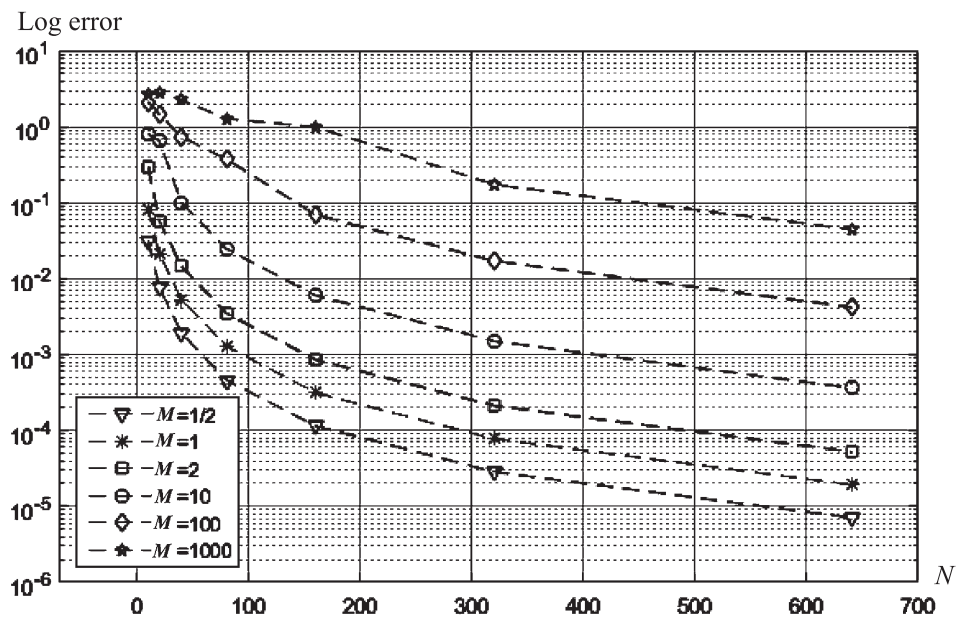

Figure 4. Error behavior for various $M$ and $h$ for Example 2 solved by the two-step method

Table 4. Three-step method error norms for Example 2 with "stable" and "unstable" values of $M$

\begin{tabular}{|c|c|c|c|c|c|c|c|}
\hline$M^{h}$ & $1 / 10$ & $1 / 20$ & $1 / 40$ & $1 / 80$ & $1 / 160$ & $1 / 320$ & $1 / 640$ \\
\hline 0.2 & $4.69 \mathrm{e}+03$ & $4.31 \mathrm{e}+11$ & $7.27 \mathrm{e}+27$ & $\infty$ & $\infty$ & $\infty$ & $\infty$ \\
\hline 0.4 & $8.61 \mathrm{e}-02$ & $2.17 \mathrm{e}+00$ & $6.90 \mathrm{e}+05$ & $6.47 \mathrm{e}+16$ & $3.51 \mathrm{e}+39$ & $\infty$ & $\infty$ \\
\hline $11 / 24$ & $3.60 \mathrm{e}-03$ & $6.12 \mathrm{e}-04$ & $8.49 \mathrm{e}-05$ & $1.10 \mathrm{e}-05$ & $1.40 \mathrm{e}-06$ & $1.76 \mathrm{e}-07$ & $2.21 \mathrm{e}-08$ \\
\hline 0.5 & $5.10 \mathrm{e}-03$ & $6.74 \mathrm{e}-04$ & $8.26 \mathrm{e}-05$ & $1.03 \mathrm{e}-05$ & $1.29 \mathrm{e}-06$ & $1.63 \mathrm{e}-07$ & $2.07 \mathrm{e}-08$ \\
\hline 0.6 & $9.80 \mathrm{e}-03$ & $1.50 \mathrm{e}-03$ & $1.79 \mathrm{e}-04$ & $2.05 \mathrm{e}-05$ & $2.41 \mathrm{e}-06$ & $2.91 \mathrm{e}-07$ & $3.63 \mathrm{e}-08$ \\
\hline $15 / 24$ & $1.12 \mathrm{e}-02$ & $1.70 \mathrm{e}-03$ & $2.24 \mathrm{e}-04$ & $2.81 \mathrm{e}-05$ & $3.53 \mathrm{e}-06$ & $4.51 \mathrm{e}-07$ & $5.67 \mathrm{e}-08$ \\
\hline 1 & $4.00 \mathrm{e}-02$ & $1.52 \mathrm{e}-02$ & $5.09 \mathrm{e}-02$ & $7.18 \mathrm{e}-00$ & $3.59 \mathrm{e}+05$ & $1.07 \mathrm{e}+16$ & $\infty$ \\
\hline 10 & $1.24 \mathrm{e}-00$ & $5.64 \mathrm{e}-01$ & $1.78 \mathrm{e}-00$ & $2.44 \mathrm{e}+02$ & $6.53 \mathrm{e}+07$ & $5.46 \mathrm{e}+19$ & $\infty$ \\
\hline
\end{tabular}




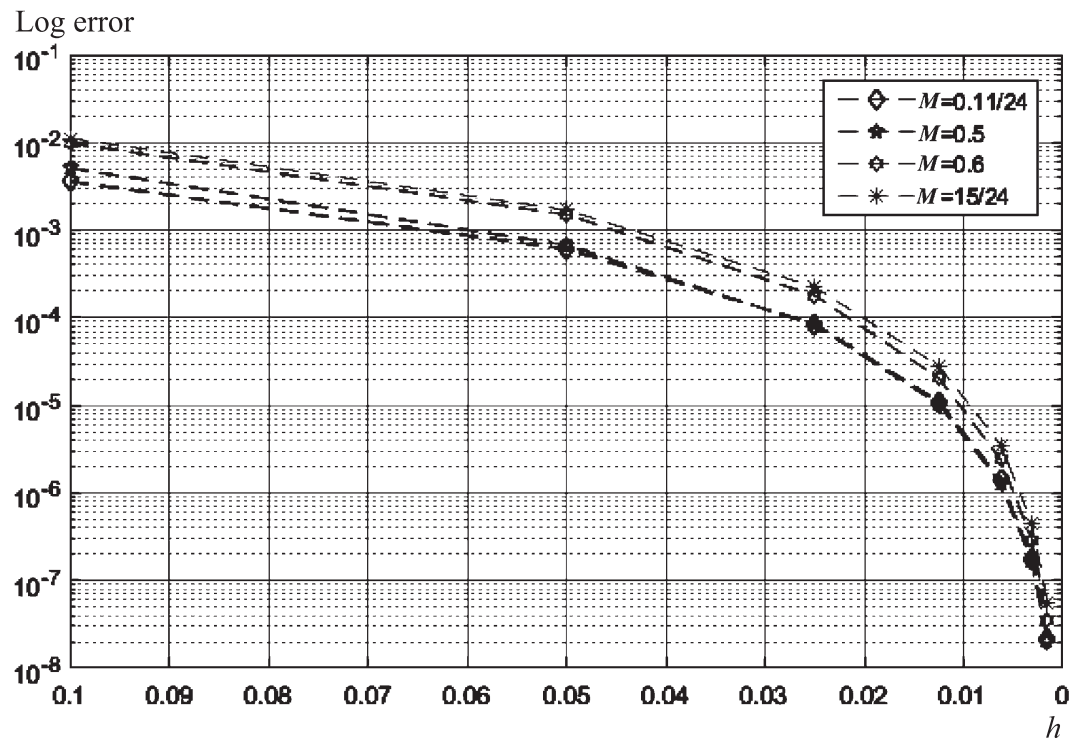

Figure 5. Error behavior for Example 2 solved by the three-step method for various $h$ and for $M$ within the stability interval

Log error

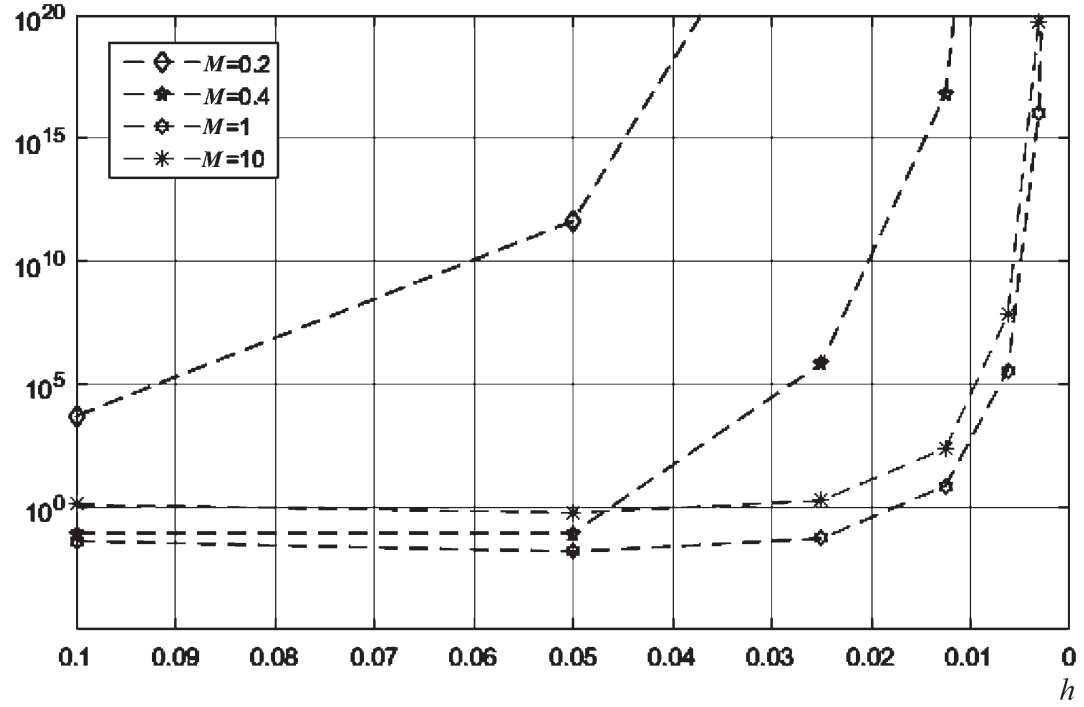

Figure 6. Error behavior for Example 2 solved by the three-step method for various $h$ and for $M$ outside of the stability interval

\section{Example 2.}

$$
\left(\begin{array}{ll}
1 & 0 \\
0 & 0
\end{array}\right) x(t)+\int_{0}^{t}\left(\begin{array}{cc}
t^{3}+s & 1-\cos s \\
t+s+2 & 5+\sin 3 s
\end{array}\right) x(s) d s=
$$




$$
=\left(\begin{array}{c}
2 \sin t+t^{3}-t^{3} \cos t-t \cos t-\frac{1}{4} \sin 2 t-\frac{1}{8} \sin 4 t+\frac{1}{3} \sin 3 t \\
t+2-2 t \cos t+\sin t-2 \cos t+\frac{5}{3}+\sin 3 t \frac{1}{6}(\sin 3 t)^{2}
\end{array}\right), \quad 0 \leqslant t \leqslant 1,
$$

with the exact solution: $x(t)=(\cos t, \sin 3 t)^{\top}$.

The results of our numerical experiments show the effects of varying $M$ and $h$ on the accuracy of the method. Note that for the two-step method the increase of $M$ negatively affects the accuracy and the convergence order of the method. For large values of $M$, the expected convergence can be observed only if we choose a small enough $h$. This is due to the fact that if $M$ is big enough, the characteristic polynomial (9) tends to have the form $\nu^{2}-2 \nu+1$, e. g. the absolute values of its roots become very close to 1 .

However, the situation is different for the three-step method. The stability interval for $M$ is very narrow: $M \in\left[\frac{11}{24}, \frac{15}{24}\right]$ vs. $M \in\left[\frac{1}{2},+\infty\right)$ for the two-step method. Choosing the optimal value of the weight parameter $M$ might be interesting from theoretical and numerical points of view. For both methods we can observe that the best convergence is obtained at the beginning of the stability intervals: $M=1 / 2$ provides best results for the two-step method, whereas $M=11 / 24$ appears to be the optimal value of the three-step algorithm. We will pay a special attention to this issue in future work.

6. Conclusion. We considered application of implicit multistep methods to solving index-1 IAEs and singled out classes of two- and three-step methods of orders two and three, correspondingly. Numerical experiments confirmed theoretical results and showed the efficiency and applicability of the methods proposed. We revealed that the stability of the algorithms can be handled by an appropriate choice of the weight parameter and experimentally confirmed it. Compared to the previous research conducted in this area [20], the new methods are able to reach a higher order of convergence, and therefore, future work suggests a more detailed analysis of the error behavior for complex ill-posed problems, as well as the construction of stable $k$-step methods of order $k(k>3)$.

\section{References}

1. Brunner H. Collocation methods for Volterra integral and related functional equations. Cambridge, Cambridge University Press, 2004, 597 p.

2. Brunner H. Volterra integral equations: An introduction to theory and applications. Cambridge, Cambridge University Press, 2017, 402 p.

3. Brunner H., Van der Houwen P. J. The numerical solution of Volterra equations. Amsterdam, Elsevier Science Ltd. Publ., 1986, 604 p.

4. Linz P. Analytical and numerical methods for Volterra equations. Philadelphia, SIAM Publ., 1985, $240 \mathrm{p}$.

5. Apartsyn A. S. Nonclassical linear Volterra equations of the first kind. Utrecht, VSP Publ., 2003, $168 \mathrm{p}$.

6. Brunner H. 1896-1996: One hundred years of Volterra integral equations of the first kind. Applied Numerical Mathematics, 1997, vol. 24, pp. 83-93.

7. Lamm P. K. A survey of regularization methods for first-kind Volterra equations. Surveys on Solution Methods for Inverse Problems. Eds by D. Colton, H. W. Engl, H. K. Louis, J. R. McLaughlin, W. Rundell. Vienna, Springer Press, 2000, pp. 53-82.

8. Ten Men Yan. Priblizhennoe reshenie linejnyh uravnenij Vol'terra pervogo roda [Approximate solution of linear volterra equations of the first kind]. PhD Thesis. Irkutsk, V. M. Matrosov Institute for System Dynamics and Control Theory of Siberian Branch of Russian Academy of Sciences Publ., 1985, 97 p. (In Russian)

9. Von Wolfersdorf L. On identification of memory kernels in linear theory of heat conduction. Mathematical Methods in Applied Sciences, 1994, vol. 17 (12), pp. 919-932.

10. Jumarhon B., Lamb W., McKee S., Tang T. A Volterra integral type method for solving a class of nonlinear initial-boundary value problems. Numerical Methods in Partial Differential Equations, 1996, vol. 12 (7), pp. 265-281. 
11. Gomilko A. A Dirichlet problem for the biharmonic equation in a semi-infinite strip. Journal of Engineering Mathematics, 2003, vol. 46 (4), pp. 253-268.

12. Liang H., Brunner H. Integral-algebraic equations: theory of collocation methods, I. SIAM Journal on Numerical Analysis, 2013, vol. 51 (4), pp. 2238-2259.

13. Zenchuk A. I. Combination of inverse spectral transform method and method of characteristics: deformed Pohlmeyer equation. Journal of Nonlinear Mathematical Physics, 2008, vol. 15, pp. $437-448$.

14. Chistyakov V. F. O vyrozhdennyh sistemah obyknovennyh differencial'nyh uravnenij i ih integral'nyh analogah [On singular systems of ordinary differential equations and their integrals analogues]. Lyapunov Functions and Applications. Novosibirsk, Nauka Publ., 1987, pp. 231-239. (In Russian)

15. Gear C. W. Differential algebraic equations, indices, and integral algebraic equations. SIAM Journal on Numerical Analysis, 1990, vol. 27 (6), pp. 1527-1534.

16. Kauthen J. P. The numerical solution of integral-algebraic equations of index 1 by polynomial spline collocation methods. Mathematics of Computation, 2001, vol. 70 (236), pp. 1503-1514.

17. Hadizadeh M., Ghoreishi F., Pishbin S. Jacobi spectral solution for integral algebraic equations of index-2. Applied Numerical Mathemathics, 2011, vol. 61 (1), pp. 131-148.

18. Pishbin S., Ghoreishi F., Hadizadeh M. A posteriori error estimation for the Legendre collocation method applied to integral-algebraic Volterra equations. Electronic Transactions on Numerical Analysis, 2011, vol. 38, pp. 327-346.

19. Pishbin S., Ghoreishi F., Hadizadeh M. The semi-explicit Volterra integral algebraic equations with weakly singular kernels: the numerical treatments. Journal of Computational and Applied Mathematics, 2013, vol. 245, pp. 121-132.

20. Budnikova O. S., Bulatov M. V. Numerical solution of integral-algebraic equations of multistep methods. Journal of Computational Mathematics and Mathematical Physics, 2012, vol. 52 (5), pp. 691-701.

21. Balakumar V., Murugesan K. Numerical solution of Volterra integral-algebraic equations using block pulse functions. Applied Mathematics and Computation, 2015, vol. 265, pp. 165-170.

22. Bulatov M. V. Regularization of singular systems of Volterra integral equations. Journal of Computational Mathematics and Mathematical Physics, 2002, vol. 42 (3), pp. 315-320.

23. Liang H., Brunner H. Integral-algebraic equations: theory of collocation methods, II. SIAM Journal on Numerical Analysis, 2016, vol. 54 (4), pp. 2640-2663.

24. Chistyakov V. F. Algebro-differencial'nye operatory s konechnomernym yadrom [Algebraicdifferential operators with a finite-dimensional kernel]. Novosibirsk, Nauka Publ., 1996, 278 p. (In Russian)

25. Bulatov M. V., Chistyakov V. F. The properties of differential-algebraic systems and their integral analogues. Preprint. Newfoundland, Memorial University of Newfoundland Press, 1997, 80 p.

26. Mehrmann V. Index concepts for differential-algebraic equations. Encyclopedia of Applied and Computational Mathematics. Ed. by B. Engquist. Berlin, Springer Press, 2012, p. 21.

27. Gantmacher F. R. The theory of matrices. Vol. I. New York, Chelsea Publ. Company, 1960,277 p.

Received: May 06, 2019.

Accepted: June 06, 2019.

Author's information:

Mikhail V. Bulatov - Dr. Sci. in Physics and Mathematics, Professor; mvbul@icc.ru

Mahmoud Hadizadeh - PhD in Physics and Mathematics, Associate Professor; hadizadeh@kntu.ac.ir

Elena V. Chistyakova - PhD in Physics and Mathematics, Fellow Researcher; chistyak@gmail.com

\section{Построение неявных многошаговых методов решения интегро-алгебраических уравнений*}

M. В. Булатов ${ }^{1}$, М. Хадизадех ${ }^{2}$, E. В. Чистякова ${ }^{1}$

1 Институт динамики систем и теории управления имени В. М. Матросова Сибирского отделения Российской академии наук, Российская Федерация, 664033, Иркутск, ул. Лермонтова, 134

2 Технологический университет имени Насир ад-Дина Туси, Иран, 19697, Тегеран, ул. Мирдамад Авеню Вест, 470

* Исследования М. В. Булатова и Е. В. Чистяковой частично поддержаны Российским фондом фундаментальных исследований (проекты № 18-51-54001, 18-01-00643, 18-29-10019). 
Для цитирования: Bulatov M. V., Hadizadeh M., Chistyakova E. V. Construction of implicit multistep methods for solving integral algebraic equations // Вестник Санкт-Петербургского университета. Прикладная математика. Информатика. Процессы управления. 2019. Т. 15. Вып. 3. С. 310-322. https://doi.org/10.21638/11702/spbu10.2019.302 (In English)

Рассматривается построение неявных устойчивых многошаговых методов решения систем линейных интегральных уравнений Вольтерра с вырожденной матрицей перед главной частью. Это означает, что такие системы содержат одновременно уравнения Вольтерра первого и второго рода. Методы решения уравнений Вольтерра первого рода к настоящему моменту обоснованы только для некоторых частных случаев, например для линейных уравнений с ядром, которое не обращается в нуль на диагонали для всех точек отрезка определения. Описываются системы, для которых ранее были установлены условия их разрешимости. Выделены классы двух- и трехшаговых численных методов второго и третьего порядков соответственно, приведены примеры, иллюстрирующие теоретические предположения. Результаты численных экспериментов показали, что устойчивость работы методов может контролироваться некоторым весовым параметром, который должен быть выбран из заданного интервала, чтобы обеспечить необходимую устойчивость алгоритмов.

Ключевые слова: системы уравнений Вольтерра, интегро-алгебраические уравнения, многошаговые методы, квадратурные формулы, устойчивость.

Контактная информация:

Булатов Михаил Валервянович - д-р физ.-мат. наук, проф.; mvbul@icc.ru

Махмуд Хадизадех - канд. физ.-мат. наук, доц.; hadizadeh@kntu

Чистякова Елена Викторовна - канд. физ.-мат. наук, науч. сотр.; chistyak@gmail.com 